\title{
Dinâmica "mitos e verdades" como estratégia de educação alimentar e nutricional de escolares: um trabalho de extensão realizado pelo Programa de Educação para o Trabalho do curso de Nutrição da Universidade Federal de Viçosa (PET-NUT/UFV)
}

Jéssica Rodrigues Morais, Juliana Farias Novaes, Francilene Maria Azevedo, Bruna Amorim Teixeira, Iasmim Xisto Campos, Mayara Fassheber Coelho

\begin{abstract}
Resumo
Na educação alimentar e nutricional, a atividade lúdica é uma ferramenta importante, devido ao seu significado na promoção da saúde e prevenção de doenças. A educação convencional pode não ter se mostrado efetiva para a modificação de hábitos alimentares adequados e para desmistificar crenças acerca da alimentação, sendo imprescindível a realização de abordagens mais significativas para os escolares. O objetivo do presente estudo foi desmistificar crenças acerca da alimentação, avaliando o processo de ensino-aprendizagem em uma dinâmica intitulada "Mitos e Verdades" desenvolvida com estudantes de uma escola municipal de Viçosa-MG. Este estudo foi realizado com escolares de 5 a 10 anos, de ambos os sexos, divididos em 5 turmas, de acordo com as séries escolares. Foi realizada a dinâmica, sendo cada sala dividida em dois grupos, os quais receberam nomes criados pelos escolares. Cada grupo recebeu duas plaquinhas, sendo uma referente a "mito" e outra a "verdade". O mediador lia as frases sobre nutrição, como por exemplo, "Faz mal não realizar o café da manhã", "Ficar em jejum emagrece", que deveriam ser julgadas e justificadas pelos participantes de acordo com a placa levantada, ou seja, como "mito" ou "verdade". Após cada resposta, realizava-se uma discussão sobre o tema abordado para complementar e reforçar as informações discutidas. Ao final da dinâmica, o grupo que obteve mais acertos recebeu um certificado como reconhecimento. Verificou-se que as crianças já possuíam um conhecimento anterior acerca dos hábitos alimentares e que esse saber foi aprimorado através da discussão de cada afirmativa, desvendando paradigmas relacionados à alimentação. Assim, foi possível impulsionar o trabalho em equipe através da reflexão entre os membros do grupo, tendo em vista a harmonia de um julgamento a respeito das afirmativas. O caráter lúdico da dinâmica permite maior comprometimento dos grupos, motivando maior troca de saberes, bem como uma promoção da saúde satisfatória. Por meio da atividade realizada, observou-se que a mesma proporcionou um conhecimento científico aos escolares, quebrando tabus e o senso comum acerca da alimentação, retificando informações errôneas. O caráter lúdico da atividade permitiu a participação dos estudantes, facilitando o processo ensino-aprendizagem e tornando-o mais significativo. Ressalta-se a importância de atividades de educação alimentar e nutricional voltadas aos escolares, a fim de promover hábitos alimentares saudáveis e sua perpetuação na fase adulta.
\end{abstract}

Descritores: educação alimentar e nutricional, escolares, lúdico. 